\title{
LA UNIVERSIDAD: SEDE DE LA RAZÓN
}

\section{Carlos Rojas Reyes}

Hernán Malo establece una relación estrecha entre razón y Universidad. Sin lugar a dudas, en este momento se establece una ligazón entre la resolución teorética de la crisis de la razón y la práctica, uniéndose ambas en un solo movimiento.

La razón halla su sede, su lugar, en el sentido hegeliano: su actualización; así, es la conclusión de un proceso unitario ontológico y ético de una razón que se realiza en la universidad.

La Universidad encuentra su preeminencia en cuanto sede de la razón, porque de las instituciones sociales, es la única en la que dos características esenciales del ser humano se encuentran como constituyentes igualmente fundamentales: el diálogo y la indagación.

La Universidad se convierte en "sede de la autonomía de la razón"; y a su vez, la autonomía de la razón respecto del Estado, se deriva de este entrelazamiento con la razón: la universidad es autónoma porque la razón expresa en ella su propia, intrínseca, autonomía. (Malo, 1985, pág. 37)

La universalidad del conocimiento, ligada a la definición de la Universidad moderna, encuentra su fundamento en este mismo hecho: la universalidad de la Universidad deriva de la universalidad de la razón.
La guía del accionar de la Universidad se origina en la razón: “Cualquier traba a la razón y sus atributos a nombre de cualquier forma de dogmatismo es un atentado a la médula de la universidad". (Malo, 1985, pág. 35)

Precisamente para romper con toda forma de dogmatismo, la razón no permanece como una unidad cerrada, irreflexiva, sino que se convierte en "razones", en todos los pensamientos filosóficos y sociales, que la cruzan y que son -o deberían ser- expresiones de la razón.

La Universidad es el plexo en donde se entrecruza lo ontológico con lo ético: todo heroísmo es posible en la Universidad. Heroísmo que deriva del compromiso con la verdad. (Malo, 1985, pág. 36)

Verdad que, a su vez, deriva de una razón que es ante todo crítica, que se vuelve en primer lugar sobre sí misma. La Universidad como lugar de la razón tiene que autocriticarse para encontrar su propia verdad. Las palabras de Hernán Malo resultan proféticas en el momento actual por el que atraviesan nuestras universidades: 
"La universidad (nuestra universidad) tiene que autocriticarse mucho más de lo que lo hace actualmente, para ejercer su condición de raciocinante". (Malo, 1985, pág. 37)

Sin esta autocrítica, toda crítica de la sociedad tenderá a aparecer como vacía, artificial, ineficaz frente a las "fuerzas que luchan por el poder". (Malo, 1985, pág. 38) Por eso, la universalidad de la razón y la razón en cuanto crítica, empatan a plenitud con la razón política:

"Una universidad no política es a la postre una universidad no comprometida con la sociedad y, al ser tal, es una universidad cercenada y carente de sentido para el hombre". (Malo, 1985, pág. 39)

De este modo, la Universidad ha devenido -con una metáfora teológica- en "cuerpo viviente de la razón".

Más allá de las lecciones que se pueden extraer de su concepción acerca de la Universidad, sobre todo en este momento en donde la crisis parece haber tocado fondo, es indispensable que observemos el movimiento de categorías que está detrás de este compromiso práctico y que lo fundamenta.

La razón que hasta este momento ha permanecido en el mundo de las abstracciones, tanto como crisis de la racionalidad greco-occidental como en cuanto búsqueda de una nueva racionalidad que rebase las limitaciones de la primera, encuentra en la propia realidad un lugar que la expresa de manera total: la Universidad.

Pero, la Universidad está lejos de ser un mero topos, una sede entendida en el sentido físico. El ser mismo de la Universidad se encuentra en la razón; las características básicas de la Universidad en cuanto institución se hallan en la razón.

Simultáneamente, en el mismo proceso, las diferentes mediaciones por las que atraviesa la Universidad, son momentos de la razón, son sus actualizaciones, son formas de una misma esencia. 
Así, las características de la Universidad: autonomía, compromiso con la verdad, razón crítica, dialéctica, práctica, expresan estas actualizaciones de la razón y por ende, la enriquecen. De lo contrario, la Universidad se mantendría dentro de un universo abstracto; por eso, esta mediación que le es inherente, encuentra aquí su desarrollo.

La razón, desde la perspectiva teorética, deviene fundamento y por ende, autonomía; y desde dicho fundamento, halla como producto de sí misma, la resolución de la contradicción entre teoría y práctica, entre universalidad y particularidad; razón y razones, entre abstracción y compromiso social, entre conciencia y política. Hernán Malo pone, así, las bases para una utopía de la razón y de la Universidad. Utopía como un no-lugar que constituye la posibilidad de todo lugar, como un mundo inalcanzable por irrealizable, que es fuente de dinamismo de la posibilidad real.

Utopía, sin embargo, que rebasa los límites de la Universidad y plantea mucho más radicalmente la posibilidad de la racionalidad del ser humano, de su capacidad de indagar y dialogar. Porque estas formas que adopta la razón en su proceso de actualización, lejos de pertenecer exclusivamente al marco de la Universidad, constituyen un deber ser general de la sociedad.

Una sociedad fundamentada en sí misma en una nueva racionalidad, que busque la verdad, que es crítica, dialéctica, política. La sociedad entera queda comprometida en la "búsqueda racional del saber", queda estructurada orgánicamente como "un cuerpo viviente, en perpetuo diálogo..."
Esta utopía, no desarrollada plenamente por Hernán Malo, constituye un aporte significativo contra aquellas corrientes que propugnan el abandono de toda utopía, de todo avance de la humanidad a la luz de la racionalidad. Ciertamente no se trata de quedarse en la racionalidad greco-occidental, a la larga demasiado comprometida con el poder dominante, pero sí de la defensa de la razón frente a la irracionalidad propuesta al menos por ciertos enfoques posmodernos.

Nota: Todas las referencias bibliográficas a Hernán Malo se basan en la edición de su libro, del año 1985. 